\title{
Entre a modernidade e a pós-modernidade: discurso e ensino*
}

\author{
Between modernity and postmodernity: speech and teaching \\ Entre la modernidad y postmodernidad: discurso y ensenãnza
}

MARIA JOSÉ RODRIGUES FARIA CORACINI**

\begin{abstract}
RESUMO - Este artigo tem por objetivo principal discutir o ensino de línguas, hoje, no contexto da chamada pósmodernidade, a partir de dois filmes e da obra $O$ mestre ignorante, de Jacques Rancière. Num primeiro momento, discute rapidamente o contexto atual da pós-modernidade, para, em seguida, discutir uma possibilidade de ensino em geral e de línguas em particular. Propõe-se refletir sobre o mestre que ignora o que o aluno sabe, mas confia nas capacidades desse aluno, posição diferente da do "mestre transmissor de conhecimentos", cujo ensino se pauta na racionalidade e se centra no professor. O mestre ignorante não indicia a falta de conhecimento na área em que atua, mas a abertura deixada por ele para que o aluno se posicione, se enganche em seu saber; o professor passa a funcionar, então, como "sujeito suposto saber", como aquele que abre espaço para o desejo do aluno, para seus interesses, para a busca de conhecimento. Não seria essa uma boa maneira de instaurar a "verdadeira" aprendizagem, aquela que passa pelo corpo e se faz corpo, tornando do sujeito o que vem do outro, transformado pela singularidade de cada um? Nesse sentido, talvez não seja possível ensinar uma língua, mas é sempre possível criar condições para que a aprendizagem ocorra, com base na escrita de si.
\end{abstract}

Palavras-chave - Ensino-aprendizagem de línguas. Escrita de si. Pós-modernidade. Subjetividade.

\begin{abstract}
This article aims, especially, at discussing language teaching today in the context of the so-called post-modernity. The discussion is based on two films and on the book Le maître ignorant, by Jacques Rancière. At first, the text discusses briefly the current context of postmodernity, to then discuss education in general and teaching languages in particular. Rancière reflects about the teacher who ignores what the students know, although he believes in their capacities. The teacher's attitudes are distinguished from the "master who transmits knowledge", whose teaching is guided by rationality and is teacher-centered. The ignorant teacher does not indicate a lack of knowledge in the area in which he operates. He wants the students to take their own positions to what concerns knowledge. The teacher turns into a "subject supposed to know", not as one who knows everything, but as one that makes room for the desire of the students, for their interests. He motivates students to search for knowledge, which is probably different from the teacher's. Wouldn't this way of relating to knowledge the "real" learning, the one which passes through the body and makes the body? Such a perspective would let the subject make what comes from the other his own, an expression of his singularity. In this sense, it may not be possible to teach a language, but it is always possible to create conditions for learning to occur, based on the writing of the self.
\end{abstract}

Keywords - Teaching-learning languages. Writing of the self. Postmodernity. Subjectivity.

RESUMEN - El principal objetivo de este trabajo es discutir la enseñanza de lenguas, hoy, en el contexto de la llamada posmodernidad, a partir de dos películas y del libro El maestro ignorante, de Jacques Rancière. Al principio se analiza brevemente el contexto actual de la posmodernidad para, a continuación, discutir una posibilidad de educación en general y de lenguas en particular. Se propone reflexionar sobre el maestro que desconoce lo que sus alumnos saben, pero tiene confianza en la capacidad de estos alumnos, posición distinta de aquella del "maestro transmisor de conocimiento", cuya enseñanza se guía por la racionalidad y se centra en el profesor. El maestro ignorante no supone una falta de conocimiento en el área en la que opera, pero en el hueco dejado por él para que el estudiante tome su posición, enganchándose a su propio saber; el maestro empieza, entonces, a trabajar como "sujeto supuesto saber", como aquel que abre espacio para el deseo del alumno, a sus intereses, a su búsqueda del conocimiento. ¿No sería esta una buena manera de establecer el aprendizaje "verdadero”, que pasa a través del cuerpo, haciendo con que el sujeto se apropie de lo que viene del otro, transformado por la singularidad de cada uno? En este sentido, puede que no sea posible enseñar una lengua, pero siempre es posible crear las condiciones para que ocurra el aprendizaje, basado en la escritura de si.

Palabras clave - Aprendizaje-enseñanza de lenguas. Escritura de si. Postmodernidad. Subjetividad.

\footnotetext{
*Este artigo se insere no grupo de pesquisa, registrado no Diretório de Grupos de Pesquisa do CNPq, "Da Torre de Marfim à Torre de Babel".

** Doutora em Ciência Linguística Aplicada pela Pontifícia Universidade Católica de São Paulo (São Paulo, SP, Brasil) e professora na Universidade Estadual de Campinas (Campinas, SP, Brasil). E-mail: <coracini.mj@gmail.com>.
} 
Neste artigo propomos uma discussão em torno do ensino de línguas (chamadas materna e estrangeiras), hoje, no contexto do que se tem chamado de pósmodernidade. É possível ensinar como antigamente, por meio unicamente da razão, da autoridade, da imposição de um conhecimento que se transmite? Como interessar os alunos no mundo dominado pela tecnologia? Trazendo-a para a sala de aula? Buscando métodos inovadores? Essas são algumas das questões que pretendemos, senão responder, pelo menos problematizar para que cada um(a) busque, na sua formação, na sua experiência, uma resposta singular, sempre provisória e sempre particular.

Num primeiro momento, teceremos algumas considerações sobre a chamada pós-modernidade, para, em seguida, discutir o ensino nesse contexto, a partir da experiência de Jacotot e da proposta de filmes, cujo enredo se passa no contexto escolar. O objetivo, portanto, deste texto é trazer uma reflexão sobre o ensino em geral e de línguas em particular, que precisa urgentemente de mudanças de posições subjetivas de alunos e professores, para que os resultados sejam mais concretos e de qualidade.

\section{ENTRE A MODERNIDADE E A (PÓS-)MODERNIDADE}

Vivemos, neste início do século XXI, a chamada era da pós-modernidade ou, nas palavras de Lipovetsky (2004a, 2004b), os chamados tempos hipermodernos. A terminologia usada - pós-modernidade, modernidade tardia, hipermodernidade, super-modernidade - não é consensual com relação ao aspecto cronológico, isto é, de que se trata de um momento posterior à modernidade nem com relação ao aspecto enfatizado por cada autor. Lyotard (1979) é considerado o primeiro a utilizar o termo "pós-moderno" para se referir à contemporaneidade: no período anterior, denominado modernidade, as grandes narrativas definiam os grupos sociais e as nações. Apesar de muito criticada e questionada, sua obra permanece um pilar importante sobre o qual se discutem as mudanças na organização da sociedade. Lyotard, em La condition post-moderne, analisa a noção de conhecimento na sociedade pós-moderna, termo ligado ao período pósindustrial, postulando que, na era pós-industrial, não há mais metanarrativas ou grandes narrativas que orientem o pensamento e a organização social. As grandes narrativas, segundo o autor, se opõem à incredulidade e ao esfacelamento de tudo na era pós-moderna. Leventhal (1991) assim comenta:

[n]a condição pós-moderna, não há mais uma forma de discurso que se sustente acima de outras; não há mais uma forma de conhecimento privilegiada que sirva de base para todas as outras. Na verdade, há simplesmente uma multiplicidade de vários jogos de linguagem, termo que Lyotard toma emprestado do último Wittgenstein. A ideia básica que Lyotard toma de Wittgenstein é a seguinte: aquilo que você deseja conhecer do significado de um termo, frase ou sentença, observe como está sendo utilizado, como ele funciona na interação humana ${ }^{1}$ (LEVENTHAL, 1991, p. 1).

Continua, com base no pensamento de Lyotard, afirmando que não há metalinguagem que envolva e sirva de apoio para os diferentes tipos de enunciados; ao lado da ciência, há muitos outros que nada têm a ver com ela, como os enunciados performativos. Essa ideia de multiplicidade de pequenas narrativas, de heterogeneidade, de descentramento e de rarefação dos discursos (FOUCAULT, 1971) constitui, talvez, a mais forte característica dos tempos pós-modernos, que Lyotard separa cronológica e ideologicamente da modernidade. Essa visão trouxe mudanças políticas e ideológicas de grande porte, dentre as quais o descentramento da autoridade, a divisão de responsabilidades, a crença em verdades de um dado momento histórico-social e não em uma verdade, universal e una.

Já mais recentemente, Lipovetsky (2004b), apesar de se posicionar a favor de uma certa imbricação entre as duas perspectivas temporais, coloca datas para o início da pós-modernidade ou da hipermodernidade, enquanto Usher e Edwards (1994), por exemplo, postulam a coexistência de ambas, sem que estejamos vivendo uma crise de paradigmas. Segundo esses autores, a educação moderna - centrada na razão e na busca da verdade científica, universal e una, no sujeito cartesiano ("Penso, logo existo"), na linguagem transparente - existe paralelamente àquela que propõe a heterogeneidade, o respeito às diferenças, o sujeito múltiplo, a linguagem opaca e caracterizada pelo equívoco. Adiantamos, desde já, que compartilhamos dessa visão, embora não concordemos com o argumento de que seriam perspectivas paralelas ou dicotômicas: a modernidade que postularia a racionalidade, a unidade e a objetividade, bem como a busca da verdade e da essência dos fenômenos, e a outra, a pós-modernidade, marcada pela dispersão, pela fragmentação do sujeito, do discurso e da experiência, isto é, a relatividade de tudo, a inexistência de uma verdade absoluta e universal, o ecletismo (CORACINI, 2003, p. 100-102). Acreditamos que a modernidade se imbrica na pós-modernidade, tanto que esta contém aquela: basta observar a composição da palavra para nos darmos conta disso.

Bauman ([2004] 2005, p. 56-58²), por sua vez, afirma que estamos 
passando da fase "sólida" da modernidade para a fase "fluida". E os fluidos são assim chamados porque não conseguem manter a forma por muito tempo e, a menos que sejam derramados num recipiente apertado, continuam mudando de forma sob a influência até mesmo das menores forças.

Essa fase fluida ele denomina modernidade líquida. Em sua obra Globalização - as conseqüências humanas, Bauman se preocupa em mostrar que a divisão entre mundo global e local, pós-moderno e moderno é uma questão de poder político e econômico. E, ao fazer isso, tece uma crítica feroz aos que se esquecem daqueles que, do outro lado do mundo globalizado, vivem dos dejetos cuspidos pelas tecnologias em constante progresso e mutação, com seus pés cada vez mais fincados em seu território, para servirem, quando muito, de objetos de curiosidade local:

Para o Primeiro Mundo, o mundo dos globalmente móveis, o espaço perdeu sua qualidade restritiva e é facilmente transposto tanto na sua versão "real" como na versão "virtual". Para o segundo mundo, o da "localidade amarrada", daqueles impedidos de se mover e assim fadados a suportar passivamente qualquer mudança que afete a localidade onde estão presos, o espaço real está se fechando rapidamente. É um tipo de provação que se torna ainda mais penosa pela insistente exibição na mídia da conquista do espaço e do "acesso virtual" a distâncias que permanecem teimosamente inacessíveis na realidade efetiva (BAUMAN, [1998] [999, p. 96).

A questão política decorrente do fenômeno da globalização e das mudanças de paradigma, segundo Bauman, abre, cada vez mais, o fosso entre o primeiro mundo e o terceiro, entre os países desenvolvidos e os países em desenvolvimento, sobretudo se observarmos que, com o desenvolvimento da mídia, o modelo a ser seguido se concentra no chamado primeiro mundo. Essa tendência tem repercussão no ensino de línguas, que não raro constrói representações idealizadas do país da língua em aprendizagem, em detrimento das representações da primeira língua-cultura.

Entretanto, todos os termos utilizados, embora lancem diferentes olhares ao mundo contemporâneo, atestam que algo resta da modernidade, já que esta se acha, inclusive, presente na sua composição lexical; a palavra "modernidade" aparece modificada por um prefixo (hiper, super, pós modernidade) ou por um adjetivo (modernidade tardia, dentre outros), Na verdade, conforme afirmamos acima, consideramos que a pósmodernidade é de uma perspectiva, um olhar que vê a realidade contemporânea atravessada pelo mesmo e pelo diferente, pela racionalidade e, ao mesmo tempo, pela fragmentação, pela dispersão (heterogeneidade) de tudo e de todos.

Mas, ainda que discordemos da permanência da dicotomia, que opõe um momento ao outro, subsequentes no tempo, é interessante retomar a visão de Lipovetsky, porque ela elucida, ainda que parcialmente, algumas características da subjetividade contemporânea. Sabe-se que a modernidade remonta ao século das Luzes, quando o homem foi colocado no centro do universo e a racionalidade vista como a única maneira de atingir a perfeição, deixando para Deus apenas a responsabilidade da criação. Os tempos pósmodernos ou hipermodernos, nos termos de Lipovetsky (2004), ao contrário, se caracterizam pela emergência das contradições ou paradoxos, pela imbricação entre a vontade de liberdade e o aumento do controle e da dependência, pela exacerbação do individualismo egoísta e, paradoxalmente, pelo crescimento de movimentos solidários que lutam em defesa da pobreza, contra a discriminação, contra toda injustiça, para citar apenas alguns.

Segundo Charles (2004), que resume o pensamento de Lipovetsky, são "o consumo de massa e os valores que ele veicula (cultura hedonista e psicologista) os responsáveis pela passagem da modernidade à pós-modernidade, mutação que se pode datar da segunda metade do século XX” (p. 23). O final do século XIX e a primeira metade do século XX assistiram ao desenvolvimento da produção industrial, ao progresso dos transportes e dos meios de comunicação, ao surgimento dos métodos comerciais que caracterizam o capitalismo moderno, como o marketing, as grandes lojas, a publicidade. Nessa fase, o consumo ainda se limitava à classe burguesa. A segunda fase do capitalismo moderno (que se inicia por volta de 1950) expande o consumo de massa para as classes menos favorecidas, permitindo que o individualismo se liberte das normas tradicionais, que se construa uma sociedade cada vez mais voltada para o presente e para as novidades, preocupada com o desenvolvimento pessoal, com o bemestar e com a moda.

A partir da década de 80, segundo o mesmo autor, a sociedade entra na hipermodernidade, em que o que move o consumo não é mais o desejo de aparecer, de mostrar status - embora saibamos que isso ainda mobiliza muitos brasileiros de médio e alto poder aquisitivo - mas, sobretudo, o desejo de sentir prazer. É o hedonismo a mola mestra dos tempos atuais: a vida é curta, precisamos aproveitar; o importante é curtir o momento presente, sem grandes compromissos com o futuro, sobretudo se eles puderem trazer riscos para a garantia da felicidade, ainda que efêmera. É esta uma das três características básicas da subjetividade nos tempos atuais (ver adiante). 
Mas, como tudo é efêmero, é preciso tirar o maior proveito de cada momento: se o importante é ter um carro último tipo, guarde-se dinheiro para comprá-lo a curto ou médio prazo; se o importante é viajar, todo esforço deve estar concentrado para esse fim. Essa economia racional, mas consumista, constitui um dos princípios do fenômeno da globalização e da ideologia neoliberal que prega o esforço pessoal como garantia de sucesso que, aliás, é medido pelo dinheiro. É nesse mundo hedonistaconsumista, voltado para o prazer e para o consumo onde todo sofrimento e todo sacrifício devem ser banidos ou minimizados -, centrado no ego, que o dinheiro - significante mestre, que agrupa uma constelação de outros significantes, funcionando como mola propulsora dos demais - oferece o acesso às chamadas "novas" tecnologias, ao progresso científico e tecnológico.

Parece incontestável que a tecnologia em geral constitui o prolongamento da tentativa milenar - que remonta aos primórdios da humanidade, pois é possível afirmar que, quando o homem, já na Idade da Pedra Lascada, constrói um instrumento para fazer fogo, ele inicia sua dominação sobre a natureza e, com ela, a própria tecnologia (do grego techné: arte); é por meio da techné que o homem atinge o que se encontra distante, o impossível, tudo aquilo que, sozinho, permanece no inatingível do sonho, da ilusão (HUTCHBY, 2001). Assim, o telefone possibilitou o contato entre pessoas a distância, na mesma cidade, no mesmo país, em países diferentes. Mais recentemente, o computador, com o qual, segundo alguns autores, interagimos, solicitando que cumpra tarefas, dele recebendo respostas e até comandos, tem facilitado o acesso às informações locais, nacionais e internacionais, além do contato com pessoas do outro lado do mundo, sem nenhum deslocamento.

Mas, como nenhuma máquina existe por si só nem age sozinha, sabemos que, escondidas, invisíveis, estão sempre a mão e a inteligência humanas a construí-la e instruí-la: as chamadas novas tecnologias constituem, desde sempre, a extensão de nossos membros (DERRIDA, 2003), limitados no tempo e no espaço, provocando em nós a sensação de que nos tornamos mais completos, inteiros, mais poderosos. O tempo se dilata, no sentido de que podemos fazer mais em menos tempo; os espaços se reduzem, aproximando o que parecia tão distante: se, há menos de 50 anos, levávamos cinco dias de navio para chegar do Brasil a Portugal, hoje, de avião - muito mais acessível, do ponto de vista econômico, à parcela da população com condições de viajar -, levamos de oito a nove horas apenas. Graças, também, aos chamados "progressos" da telefonia, que de fixa passou a móvel e desta, ao celular, conseguimos falar com alguém (a viva voz) que se encontra no Japão ou na Europa, imediatamente, ao simples digitar do número, em melhores condições até do que falamos com nossos vizinhos. E tudo isso graças ao desenvolvimento da tecnociência.

Graças, ainda, ao chamado "avanço" tecnológico que, evidentemente, resulta do que se costuma denominar "progresso"3 da ciência - daí sua legitimação que soa à maioria de nós como inquestionável -, a sociedade capitalista, isto é, empresários e comerciantes, apoiados pelo marketing e, consequentemente, pela ânsia de aumentar o consumo, têm oferecido inúmeras facilidades que encantam a todos os cidadãos, facilidades essas que vão construindo, incessantemente, necessidades, que, por sua vez, vão aos poucos se naturalizando, de modo que o cidadão brasileiro de classe média - e, em certa medida, até mesmo o de classe pobre - não consegue conceber a vida sem aparelhos como telefone, celular, televisão, rádio, vídeo, dvd, tv a cabo, geladeira, fogão a gás ou elétrico, micro-ondas, lava-louças, máquina de lavar roupa, secadora e assim por diante. Parece óbvio, embora nos esqueçamos, que tais facilidades deixam paulatinamente marcas visíveis no corpo, provocando, ao longo do tempo, além de mudanças psíquicas, mudanças físicas, como a atrofia muscular, pela economia dos movimentos, o que, por outro lado, gera a valorização da educação física como uma maneira (pós-)moderna de dirimir os efeitos de tal fenômeno.

Como se isso não bastasse, dando prosseguimento ao processo de construção de necessidades, o mercado, que não pode esmorecer, não se satisfaz com a simples promoção da aquisição de mercadorias, mas oferece sempre novos aparelhos ao consumidor, oriundos de modificações incessantes ou atualizações que vão, por sua vez, apontando para novas necessidades ou para a "necessidade" - já naturalizada em cada um, graças à ação da mídia - de trocar rápida e constantemente os aparelhos; afinal, somos todos estimulados a acompanhar o que chamamos de "evolução" ou "progresso" ou "moda". A título de exemplo: um menino de 11 anos afirma o seguinte, em uma entrevista ao Estado de São Paulo (10/10/2005): "Gostaria de ter um celular [X]. É chato ter um celular ultrapassado". Vera, sua mãe, diz que não tem condições de comprar um aparelho caro. Notese que a denegação ("não tenho condições...") aponta para o desejo da aquisição, explicitado a seguir: "Mas, se pudesse comprava um com localizador, para saber onde ele está". Ora, ao lado de um consumo de massa exacerbado, propaga-se a liberdade, como um efeito da (pós-)modernidade que, ao deslocar Deus do centro do universo, como causa de tudo, coloca ênfase na livre escolha: afinal, trabalhamos e podemos comprar o que quisermos de acordo com nossas posses; mas, ao lado disso, ou melhor, ao mesmo tempo, como é possível perceber no exemplo acima, exacerba-se o controle de um pelos outros, o controle da mídia, do marketing sobre 
o consumidor, que, por sua vez, se vê instigado a controlar os filhos na escola ou na rua, o morador de um prédio, os transeuntes na rua, os outros internautas.

Não é sem razão que Bauman ([2000] 2001, p. 16-22) afirma que estamos na era do pós-panóptico ou do sinóptico - um indivíduo se vê controlado por múltiplos olhares - e não mais na era do panóptico tão discutido por Foucault (1975), em que um controlava vários indivíduos ao mesmo tempo, em que os indivíduos eram submetidos a uma vigilância organizada e coordenada, na prisão, na escola, na família. Hoje, a multiplicidade de olhares e a sua volatilidade dificultam o poder disciplinar, ao mesmo tempo em que exercem uma vigilância ainda maior, embora imperceptível, subliminar. É para isso que aponta o exemplo acima da mãe que declara querer "saber onde o filho está" e dos pais que cada vez mais tendem a instalar em casa ou no escritório uma câmera, para saber, ou melhor, "ver" como o(a) filho(a) se comporta na escola e como o professor reage e ensina. Não faz muito tempo, soube-se que uma mãe telefonou para a escola, dizendo que não queria que sua filha (de 5 ou 6 anos) andasse descalça, como reação a uma cena que acabava de assistir, de seu escritório, pela câmera. Aliás, a esse respeito, é interessante observar que internalizamos a necessidade de vigiar os outros e, muitas vezes, não nos damos conta de que estamos também, cada vez mais, submetidos aos olhares alheios que invadem, inclusive, nossa privacidade: pela internet, pelas câmeras instaladas nas lojas, nos edifícios, nos elevadores, nas máquinas eletrônicas dos bancos, nos supermercados etc., embora, no discurso, que é sempre semblante (LACAN, [1971] 2009), tudo isso tenha o objetivo de nos proteger da violência urbana, de roubos, assaltos, incômodos.

Simultaneamente a toda essa vigilância e a todo esse assédio ao consumo - que se faz até mesmo por telefone-, estamos nos tornando prisioneiros, escravos da tecnologia e, por extensão, do computador e da internet, uma das "aquisições" mais modernas e mais assustadoras de nossos tempos, que está, inclusive, pouco a pouco, substituindo outros aparelhos ou meios de comunicação como o telefone, o correio, o jornal, a televisão e o cinema, chegando a constituir um veículo (talvez o mais utilizado nos dias de hoje e reconhecido pelas instituições de ensino) de conhecimento, provável substituto das famosas e antigas enciclopédias, dos livros e - por que não? - dos próprios professores, que passam a tutores no ensino a distância (EaD), até mesmo no ensino fundamental. A esse respeito, não raro ouvimos da boca de alunos expressões do tipo: "A internet é tudo" ou "Tudo o que queremos encontramos lá" ou ainda: "Fazemos nossas pesquisas na internet". Tais atitudes e outras mais colocam a internet e as máquinas em geral num pedestal, que não lhes é apropriado, assim como também não parece apropriado o lamento, vão e impotente, que desejasse um impossível retorno ao passado, anulando o inevitável; afinal, as chamadas novas tecnologias constituem uma escritura, a escritura dos nossos tempos, dos tempos pós-modernos ou mesmo hipermodernos e, como toda escritura, esta também é, a um só tempo, remédio e veneno (DERRIDA, 1991), benefício e prejuízo para a humanidade.

No mundo, portanto, dominado pelo que chamamos novas tecnologias que modificaram a relação do homem com o tempo e o espaço, é possível ensinar como antigamente? Deve a escola reforçar a ausência de valores, a incredulidade de que fala Lyotard (1979), características da pós-modernidade, marcada, hoje mais do nunca, pela atrofia do simbólico e, ao mesmo tempo, pela expansão do imaginário - que se constitui de representações de si e do outro, com base na moda, na aparência, no espetáculo, na pertença a um grupo - ou é preciso, de algum modo, fazer emergir o desejo que carrega consigo a falta, levando o ser humano à busca, ainda que vã, de sua realização? Parece aos psicanalistas (MELMAN, 2002) que sim: se não é possível apagar as consequências da pós-modernidade, que, na escola, se faz sentir pela indisciplina, pelo desrespeito, pelo desinteresse pela manutenção das regras, valores antigos, do ensino lento e monótono que enfatiza a gramática, o vocabulário, as estruturas feitas para serem repetidas e memorizadas, ao mesmo tempo em que se desenvolve no jovem o individualismo, a falta de valores, o apego ao descartável, a impaciência, e, como decorrência, a tendência à depressão, ao desamparo, talvez seja interessante despertar, no estudante, o desejo nele adormecido, valores ofuscados, objetivos de vida apagados, favorecendo, assim, a emergência do sujeito do inconsciente (ou da falta ou do desejo), como propõe Lacan para construir um futuro, obviamente diferente do passado e do presente, em que cada um possa assumir com responsabilidade e criatividade a própria vida e o rumo da sociedade. É com o intuito de discutir essa questão política e polêmica que passamos à segunda seção deste texto.

\section{REFLEXÕES SOBRE O ENSINO (DE LÍNGUAS)}

Neste item, considerando o momento históricocultural em que estamos vivendo, propomos uma reflexão sobre uma possível mudança de posição do(a) professor(a) de língua (portuguesa ou estrangeira), da posição tradicional de um saber - ou, melhor, de um conhecimento totalizante -, que se apoiava na dicotomia professor/aluno, fonte do saber/ignorância, para a posição subjetiva de professor ignorante, tal como concebe Rancière (2010). A primeira posição se caracteriza pela consciência que tem o professor de seu conhecimento, 
em detrimento do não saber do aluno, configurando sua função de transmissor, de intermediador entre o livro didático ou um dado conhecimento e o aluno, com o objetivo de facilitar, tornar palatável, explicar o que sabe, de modo que o aluno compreenda, repetindo, decorando e, assim, assimilando. Essa posição não é a do professor medíocre; pelo contrário, é a do professor zeloso, preocupado com o seu saber para transmiti-lo (trans-mittere $=$ passar para o outro lado) aos alunos; representante do ensino tradicional, responsável, desejoso de manter sua autoridade, para garantir a disciplina e o respeito. Isso ocorre em qualquer disciplina, mas a frequência da metodologia baseada na repetição de estruturas, nos aspectos gramaticais e lexicais, ainda que de forma camuflada pela abordagem comunicativa, parece ainda mais presente. Consciente da ignorância do aluno, que sabe pouco ou nada, se comparado ao mestre, o chamado professor tradicional procura preencher sua falta, para, logo em seguida, cavar outro buraco, que, uma vez mais, busca preencher e, assim, sem cessar, cavando, incessantemente, o fosso entre o mestre e o aluno, com base no poder que assume, como professor legitimado e autorizado pela instituição escolar, pela sociedade e pelo grupo de alunos. Nessa posição, o professor garante o sua função de explicador, o seu poder de levar o aluno a compreender e aprender o conteúdo a ser ensinado, ainda que nem sempre isso ocorra.

Entretanto, é preciso considerar que essa necessidade do aluno com relação ao saber do professor é, ao mesmo tempo, uma construção social, para garantir uma formação controlada (por alguns, diga-se de passagem) - o aluno aprende o que se quer que aprenda -, necessidade essa que se vê, em nossos dias, cada vez mais questionada por um mundo esvaziado de valores e dominado pelas chamadas novas tecnologias, que tornam a vida mais fácil, exigindo pouco do jovem em termos intelectuais. Paralela e consequentemente, o jovem vive o desamparo deixado em cada um pela morte do Pai simbólico - a princípio Deus, que transmite(ia) seu poder de ordenar, explicar e justificar, ao pater familias, ao padre ou ao pastor-, morte essa que culminou no nascimento da ciência (BIRMAN, 2001), centrada no homem e, portanto, no instável e inseguro, embora sob o simulacro da estabilidade, da segurança e da verdade. O ser humano se encontrava, assim, na zona movediça e escorregadia do entremeio: entre a ilusão de estabilidade, liberdade e segurança (afinal, agora, é o homem que busca a verdade dos fatos, sem precisar se submeter a um Deus, imprevisível, de atitudes surpreendentes e temíveis) e a necessidade das mesmas para se sentir estável, livre e seguro, o que só pode advir de um ser supremo, capaz de proteger o homem de todo e qualquer mal e de preencher toda e qualquer falta, sobretudo nos momentos mais incertos, de maior solidão.
Seguindo procedimentos metodológicos precisos e rigorosos, segundo uma progressão ordenada, do mais simples para o mais complexo, sem se perguntar a pertinência dessa dicotomia clássica, disciplinadora (FOUCAULT, 1975), o professor de língua chamada materna ou estrangeira leva(va) o aluno a galgar, paulatina e progressivamente, degraus em direção à verdade do mestre, à completude do conhecimento, sem, paradoxalmente, poder alcançar o patamar mais alto, representado pelo professor: afinal, para que o mestre exista é necessário que o aluno a ele se submeta; para que o mestre garanta o seu poder, que advém de um saber acadêmico ou científico e de uma autoridade incontestáveis, é preciso que o aluno aprenda o que o professor ensina e se restrinja a esse saber. Trata-se do discurso do mestre de que fala Lacan ([1971] 2009).

A aula de língua estrangeira tem a peculiaridade de garantir essa dicotomia: o professor sabe falar, compreender e escrever na língua que ensina, enquanto o aluno aos poucos, de acordo com o nível em que se encontra, vai assimilando as formas linguísticas segundo uma progressão prevista que, em vez de liberar, constrange o aluno, limita as suas possibilidades.

Como já afirmamos, Rancière enfatiza que não é o aluno que precisa do mestre, mas este é que precisa do aluno, para garantir a sua existência, tal como Lacan (1992) que, ao retomar a dialética do senhor e do escravo em Hegel, dialética necessária para que o mestre atue como tal e que o escravo o reconheça como tal, esclarece que é o escravo quem garante a posição do mestre. Tal afirmação se ancora numa experiência vivida no início do século XIX, por volta de 1818, pelo professor francês, filósofo, filólogo, político, Joseph Jacotot, quando, tendo sido destituído de seu poder político pelo retorno dos Bourbons, se viu na condição de exilado nos Países Baixos, país que o recebeu de braços abertos em Louvain, em cuja universidade passou a lecionar, em meio período, a disciplina Literatura Francesa para alunos de língua holandesa (ou flamenga), que pouco ou nada sabiam de francês. Jacotot, por sua vez, nada sabia de flamengo nem estava interessado em aprender. Para espanto seu, sua fama se espalhou pelas redondezas da cidade e logo acorreram muitos alunos. O experiente professor, sem saber como proceder nessa situação esdrúxula, viu-se na contingência de ter de construir uma estratégia, a fim de criar um campo comum entre ele, que não conhecia a língua dos alunos, e o grupo de alunos, que nada sabia de francês. Nessa ocasião, saiu uma versão bilíngue (francês-flamengo) de Telêmaco, de Fénelon, obra que, embora não fosse a mais significativa para a disciplina sob sua responsabilidade, trouxe-lhe a saída de que tanto necessitava: pediu aos alunos que lessem o texto em francês e que, apoiados na tradução para o flamengo, o 
compreendessem, para, só depois, falarem com ele sobre a obra em língua francesa.

Quando estavam no meio da tarefa, pediu-lhes que repetissem inúmeras vezes a leitura dessa primeira metade e que lessem a outra parte para compreenderem todo o texto, a ponto de falarem sobre ele em francês. Como se isso não bastasse, quando os alunos estavam prontos, passoulhes a tarefa de escreverem em francês o que cada um havia entendido e de opinarem a respeito da obra. Pensava o sábio mestre que seus discípulos iriam cometer erros bárbaros em língua francesa, a tal ponto que seria difícil, para não dizer impossível, compreender as produções escritas, já que não haviam tido nenhuma explicação nem de verbos nem de ortografia nem da sintaxe da língua francesa, tão diferente da sua, assim chamada língua materna. Qual não foi sua surpresa quando se deparou com textos sólidos, escritos num francês semelhante ao de muitos nativos! Como compreender esse fenômeno? Como é possível apre(e)nder uma língua sem a presença e o auxílio de um professor? Algo escapava à lógica e ao controle, algo permanecia inexplicável.

Será, então, que os alunos não precisavam mais dele, se é que, algum dia, de fato, haviam precisado? Angústia de um mestre que se considerava central no processo de ensino-aprendizagem, baseado no logos, nos moldes racionais do Século das Luzes, representado, em particular, por Descartes. E Jacotot, como muitos franceses ainda neste início do século XXI (e não só franceses!), se mantinha fiel a essa visão tradicional. Mas, agora, estava vivendo um impasse e a dúvida (não a cartesiana, lógica, racional) passou a habitá-lo. Lacan ([1966] 1998b) diria que aí se produziu uma metáfora, uma condensação de sentidos que, graças à sensibilidade do mestre Jacotot, deu lugar a uma ruptura, que é sempre angustiante, porque coloca o sujeito diante de perguntas sem resposta, diante do incontrolável, do incontornável: como explicar um fenômeno que escapa à Razão que sempre recobriu o conhecimento científico e o ensino? Talvez essa mesma constatação tenha levado Freud ([1920] 1987) a considerar a (im)possibilidade de educar, psicanalisar e governar; afinal, o inefável, o fugidio, constitui cada um desses domínios. E Jacotot, sem saber, se viu diante de subjetividades que escapavam ao seu controle. No ensino de línguas, ainda hoje, muito do que os alunos (in)corporam tem a ver com a inscrição de cada um nas discursividades da língua-cultura do outro que, por sua vez, passa a constituir o sujeito. Quando isso acontece, o professor pouco tem a fazer (CORACINI, 2014), porque o aluno passa a adentrar e apre(e)nder a língua que lhe é estranha tanto quanto sua língua primeira...

Rancière $(2010$, p. 23) comenta a respeito da experiência de Jacotot:
A revelação que acometeu Jacotot se relaciona ao seguinte: é preciso inverter a lógica do sistema explicador. A explicação não é necessária para socorrer uma incapacidade de compreender. É, ao contrário, essa incapacidade a ficção estruturante da concepção explicadora do mundo. É o explicador que tem necessidade do incapaz e não o contrário; é ele que constitui o incapaz como tal.

Explicar algo a alguém é revelar-lhe sua incapacidade, sua impossibilidade de pensar e aprender por sua própria inteligência, segundo suas potencialidades e segundo sua história de vida, o que solidifica a existência de um mundo baseado em dicotomias (sábio vs ignorante, capaz vs incapaz, inteligente vs bobo, racional vs irracional, professor vs aluno), constitutivas da epistemologia ocidental, desde seus primórdios, alicerçados nos preceitos da Antiguidade greco-latina. Nessa crença, ancora-se o mito pedagógico do sujeito centrado, racional, do professor competente, que tem por função tirar o véu da ignorância dos alunos, fazendo-os des-cobrirem o mundo à sua volta, ou melhor, no caso em questão, o mundo do outro, da língua-cultura do outro, que admira porque deseja.

Jacotot aprendeu com essa experiência que é possível ensinar o que não se sabe ou o que não se sabe ensinar, desde que o professor coloque sua autoridade a serviço do seguinte princípio: seus alunos são tão inteligentes e capazes quanto ele, que, por sua vez, se encontra, como seus alunos, em contínua aprendizagem. Afinal, ele também é sujeito da linguagem, sujeito do desejo e, portanto, sujeito da falta, da falha que não o abandona, apesar de sua busca incessante por uma completude impossível.

Cabe, aqui, uma outra reflexão a partir dos filmes "Pro dia nascer feliz", ${ }^{4}$ documentário brasileiro, dirigido por João Jardim e produzido por Flávio Tambellini, sobre o dia a dia de alunos em Pernambuco, São Paulo e Rio de Janeiro, em escolas públicas e privadas, mostrando o conflito do jovem, as suas expectativas ou a sua desesperança, o fosso entre escolas para ricos, mesmo que sejam confessionais, e escolas para pobres, a atitude dos professores e dos alunos entre si e entre eles e os professores -, e "Escritores da Liberdade", 5 filme norteamericano que narra o cotidiano de uma professora que, ao mudar de cidade com seu marido, se encontra numa escola de periferia, com alunos em sua maioria negros, com um passado de violência: estupro, homicídios, senão vividos, sofridos (morte da mãe, do pai ou de outra pessoa querida); alunos arredios, desobedientes, que não têm nenhum interesse em esconder a sua insatisfação e, principalmente, o seu desinteresse por qualquer tipo de aula.

Se o filme brasileiro mostra a displicência dos professores, que faltam o tempo todo, deixando os alunos 
na rua, o desinteresse da maioria dos alunos e o interesse de outros, mesmo nas escolas públicas de periferia, sugerindo, ainda assim, a diferença de tratamento nas diferentes classes sociais, o segundo filme fala de uma situação muito pertinente: diante da impossibilidade de trabalhar com a classe, alunos rebeldes e desinteressados, a professora, que não conseguia dormir de tanta preocupação, por causa da atitude agressiva e arredia dos alunos, que não esboçavam o mínimo interesse por ela ou por sua matéria (no caso, língua inglesa, primeira língua para a maioria dos alunos) nem sequer se davam conta de sua presença em sala, decidiu assumir a posição de quem se interessava por eles (interesse que o filme apresenta como sendo sincero). Propôs, então, atividades, aparentemente banais, como apresentar-se um ao outro, para que os colegas e ela mesma possam conhecê-los, saber de onde vêm, o que fazem. Foi, assim, aos poucos, mostrando-se afável com cada um e ganhando a sua confiança. É preciso lembrar que eles estavam acostumados com professores que funcionavam como informadores, sem demonstrarem nenhum interesse por eles enquanto pessoas.

Mas, o que mais chama a atenção em todo o filme é a criatividade da professora: como fazê-los ler e escrever, se não demonstravam nenhum interesse? Meio por acaso - um pouco à maneira de Jacotot - pensou em fazer uma experiência: comprou um livro para cada aluno, de seu próprio bolso, e o deu de presente, já que nem a bibliotecária da escola nem a diretora permitiam que livros fossem retirados para leitura em casa, porque os alunos, sujos, relaxados e indisciplinados, estragariam os volumes e não haveria dinheiro para repô-los. Os alunos se sentiram satisfeitos com o presente - afinal, essa era primeira vez que ganhavam um presente na escola - e se puseram a ler e a trocar os livros com os colegas. A segunda tarefa envolvia a escrita: a professora pediu que escrevessem sobre eles - sua vida, seus interesses, seus problemas - num caderno que ela também comprou e lhes deu de presente. Os cadernos ficariam no seu armário, fechados a chave; se eles quisessem que ela lesse, bastava deixar o caderno sobre sua mesa; caso contrário, ela respeitaria a privacidade de cada um. Nos primeiros dias, como seria de esperar, ninguém deixou o caderno sobre a mesa da professora; aos poucos, foram ganhando confiança e deixando o seu diário para que ela o lesse. É o que se pode denominar escrita de si. Sem corrigir, porque não era sua intenção, para não tolher a sua capacidade de escrita, ela foi conhecendo melhor cada um e se aproximando deles, a ponto de um dia saírem juntos para um passeio organizado por ela. Sua vida se resumia a ajudar seus alunos a lidarem com seus traumas e recalques, talvez seus sintomas, em prol de sua criatividade, que Lacan ([1975-1976] 2007) denomina "singularidade": fazer algo com seu sintoma, de modo a oferecer seus serviços ou suas habilidades ao outro. De agressivos os alunos passaram, aos poucos, a interessados por tudo o que lhes era oferecido e, o melhor, ganhavam, lentamente, confiança em si mesmos, em suas capacidades, em suas possibilidades de romper com o que parecia estar previamente destinado a cada um deles que, por serem excluídos da sociedade hegemônica, se anulavam, percebiam-se nulos aos olhos do outro - rico e poderoso -, que dita as regras e as leis sociais.

\section{TransferêNCIA E ESCRITA DE SI}

Kupfer (1992), em seu texto "Freud e a Educação", afirma algo que coincide com nosso modo de ver a relação professor-aluno-língua a ser ensinada-aprendida: a relação entre professor e aluno não deveria estar focada no "valor dos conteúdos cognitivos que transitam entre duas pessoas" (p. 85); não está na informação que é transmitida de um para o outro, como no regime racional - que não configura apenas a metodologia adotada, mas a política centralizada, autoritária -, não está na metodologia adotada, por mais importante que ela pareça ser, mas nas relações afetivas, que, mais adiante, no mesmo texto, ela nomeia "transferência", um pouco nos moldes da transferência na análise clínica. A transferência, tanto na clínica quanto na escola, parte do analista ou do professor, que engancha o analisando ou o aluno no seu saber e no amor por ele. André (2014, p. 40) afirma, retomando as palavras de Lacan, que "o desejo do homem é o desejo do Outro, o que leva o ser falante a pedir ao Outro um signo de seu desejo".

Depreende-se do texto de Rancière que o professor não precisa ter um conhecimento supremo para abrir as portas do conhecimento ao aluno, mesmo porque o conhecimento deste pode muito bem ultrapassar ou ser diferente do seu. Não há dúvidas de que o professor é necessário, porque há sempre necessidade do outro para estabelecer uma relação com o conhecimento, mas de um outro que não seja ditador, que não assuma a posição daquele que sabe tudo e, por isso, tem de mostrar o que sabe a quem não sabe nada e que, portanto, precisa das explicações do mestre. Lembremo-nos que a criança aprendeu a chamada língua materna sem necessidade de um explicador; ela mesma construiu seu método, sem saber, repetindo, tateando, comparando, corrigindo; e tudo isso, sob o estímulo afetivo da mãe que deu sentido a seus ruídos, a seu choro, a suas necessidades, introduzindo-a no mundo simbólico e tomando-a como sujeito, mesmo quando sua subjetividade ainda não estava instaurada, mesmo quando o bebê ainda não se submetia à linguagem, imerso no sentimento oceânico do narcisismo primário. A mãe confia no(a) filho(a), no que o(a) filho(a) é capaz e desafia-o(a) a aprender uma língua que é dela, herdada por ela, e, como tal, a chamada língua materna 
(da mãe) lhe será sempre estrangeira, sempre do outro e, ao mesmo tempo, sempre sua. $\mathrm{O}(\mathrm{A})$ professor(a) não tem de ocupar a posição de mãe, mas pode funcionar como alguém que confia na capacidade do aluno, que sabe que nem tudo depende dele(a), que aprender uma língua é muito mais do que simplesmente repetir formas linguísticas.

O amor de transferência, que parte do sujeito suposto saber para sustentar a identificação (ANDRÉ, 2014, p. 42), se faz, então, necessário tanto na relação analistaanalisando quanto na relação professor-aluno, para que algo aconteça, para que o desejo de cada um aflore e se realize, a partir do desejo do analista ou do professor, ainda que nunca em sua totalidade, mesmo porque ninguém sabe exatamente qual é o desejo que o(a) constitui. Isso exige que o professor assuma a posição de suposto saber (o analisando ou o aluno toma o saber que se constitui no Outro como o signo de seu desejo (ANDRÉ, 2014, p. 40), isto é, que o aluno nele confie, acredite que ele sabe resolver o seu problema, que ele sabe mais. Nesse caso, o(a) professor(a) não é aquele(a) que sabe tudo e que se compraz com esse saber, não abrindo ao aluno espaço para que ele se coloque, para que ele construa seu caminho, para que ele também se posicione frente ao conhecimento.

$\mathrm{O}(\mathrm{A})$ professor(a) tem amor pelo aluno, pelo que faz, tem paixão pelo que ensina, sem a cegueira de quem vê no outro, na língua-cultura do outro, a perfeição, o paraíso, capaz de desvalorizar a sua própria língua-cultura, sabe resolver as tarefas por ele solicitadas; se assim não for, não ocupará jamais o lugar de sujeito suposto-saber. Da mesma forma, se o professor se mantiver na posição daquele que sabe tudo, ainda que se depare, vez por outra, com sua falta, com suas falhas, com a impossibilidade de saber uma língua-cultura na sua totalidade, nem mesmo aquela que denominamos língua materna, jamais colocará o aluno na posição de aprender, de pesquisar, de realizar o seu próprio desejo (e não o desejo do adulto que quer controlar, dominar, ser senhor da situação), de ser criativo no sentido de dar vazão ao seu sinthoma, fazendo de e com o seu sintoma, como afirma Lacan (2007), algo que o singularize, que o realize, que o torne diferente dos demais, ao mesmo tempo em que com eles guarda semelhanças, sobretudo se compartilharem do mesmo momento histórico-social, das mesmas crenças e valores. Abrir o caminho da aprendizagem ao aluno, que se engancha e engancha o seu desejo no desejo do mestre, é a grande tarefa, para não dizer a única, que ao professor de qualquer disciplina, mas sobretudo de línguas, cabe assumir, para que - fazendo um trocadilho - seu aluno não suma, não desapareça, debaixo de um saber totalizante e, portanto, inatingível... Se o desejo do mestre é fazer emergir o desejo do aluno, que tem a ver com o saber a língua-cultura do outro, então, o aluno, enganchando-o no seu desejo, sentirá prazer em apre(e)nder, modificando o seu saber e o seu ser, sem deixar de ser o que sempre foi (o mesmo e o diferente).

Por sua vez, o filme que comentamos representa bem o que gostaríamos de mostrar a respeito do ensinoaprendizagem em geral e de uma língua em particular, não apenas com alunos de periferia de escolas públicas, onde não raro nos confrontamos com alunos revoltados, desinteressados de tudo, sem motivação alguma, querendo ter o que não podem ou não conseguem ter, mas também com alunos de escolas particulares, de classe média que, vivendo no mundo das novas tecnologias, da aparência e do dinheiro que assume o lugar de Deus ou de uma autoridade legitimada, vivem o desamparo, a solidão, mesmo em meio à multidão de "amigos" virtuais que cresce a cada dia e da qual eles se orgulham sem saber bem por que; afinal, estão sós, diante de um computador que não lhes dá a satisfação de uma relação pessoal com o outro, perdendo cada vez mais a capacidade de se expressar, de se dizer, de fazer elo, de assumir a responsabilidade por si e pelo outro.

Trata-se do sujeito do consumo, do imaginário, das aparências, do gozo (MELMAN, 2002), como comentamos na primeira parte deste ensaio. Não estamos lastimando, porque não há de que se lastimar: desde que o mundo é mundo, ocorrem mudanças, e essas mudanças apontam sempre para deslocamentos identitários, que deixam marcas, por vezes, irreversíveis, na sociedade e em cada sujeito. Mas, se não tivermos um comportamento histérico e saudosista, teremos vontade de desenvolver nesses jovens valores que os levem a querer viver, a ter um objetivo, a assumir a responsabilidade da própria vida, ainda que, não seja tão fácil assim no paradigma da pós-modernidade.

Também não desconhecemos a formação do professor que, no Brasil, ainda hoje, se vê desvalorizado, desmotivado, cansado de tanto trabalhar, de se empenhar para que o aluno aprenda. Como exigir que esse professor seja criativo, interessado, solidário, se ele tem de trabalhar em três turnos para poder sobreviver dignamente? Como exigir que o professor assuma a posição do professor "ignorante" no sentido que Rancière empresta ao termo, ou a posição da professora americana, disposta a tudo para conquistar a confiança de seus alunos problemáticos, se só encontram seus alunos algumas vezes por semana? Se têm salas de 40 alunos e várias turmas? Não temos dúvida da dificuldade e até da (im)possibilidade. Para isso, é preciso, no mínimo, modificar os cursos de formação na universidade (pré-serviço) e após ela (em serviço), refletir sobre o ensino unicamente centrado na cognição, na razão, na explicação científica como a única verdade, enganchando-o no seu desejo. E, antes de 
mais nada, modificar suas representações a seu respeito e a respeito do outro (aluno), não abandonando, mas deslocando sua autoridade, de sujeito do conhecimento para sujeito suposto saber, único capaz de estimular, no aluno, a vontade de saber.

E, na aula de línguas, promover a escrita de si - ou, melhor, a escritura -, tal como Derrida ([1972] 1991) postula em A farmácia de Platão, inscrição de si, de sua subjetividade tanto na oralidade quanto no que se convencionou denominar escrita. Foucault (1992) também se pronuncia sobre a escrita de si, como um modo não apenas de dizer, mas de dizer-se, posicionar-se, sem repetir desnecessariamente a opinião alheia, expor-se ao expor, ao permitir que algo de si se presentifique a ponto de fazer da vida uma obra de arte. Mas a escrita de si, como mostram os filmes aqui comentados, não tem por função apenas expor-se; ela permite que o aluno extravase seus sentimentos, seus traumas e, quem sabe, seus recalques. Dizendo ou escrevendo sobre si - o que ocorre de forma evidentemente diferente na clínica psicanalítica, mas guardando com ela alguma semelhança - é o sujeito que emerge, servindo-lhe de catarse. Sabemos de alguns exemplos em que a escrita impediu que atrocidades fossem cometidas ou poderia ter impedido (CORACINI, 2005), o que ocorreu com um compositor pianista que não matou a namorada que o traía em Paris porque extravasou sua revolta numa peça musical; Pierre Rivière (FOUCAULT, 1997) não teria, muito provavelmente, degolado a mãe, a irmã e seu irmãozinho se tivesse escrito o seu plano antes de cometer os crimes para salvar seu pai da ação exploradora da mãe. Quando se fala de escrita, não se quer apenas referir à prática escolar da escrita, mas à escrita livre das amarras da escola, escrita essa que se expressa no papel através de sinais gráficos, na pintura, na musica, enfim nas artes. Freud ([1930] 1987) chamou a isso de "sublimação" - colocar sua energia na arte, na ciência, nos estudos, na religião, em vez de se deixar tomar por atos de violência - e Lacan, de sinthoma - fazer algo com seu sintoma, algo de singular, de diferente, para si e para o outro, de modo a ser produtivo.

Estudar uma língua, nela se aperfeiçoar, fazê-la passar pelo corpo e dela fazer corpo, inscrevendo-se na línguacultura do outro, é um dos modos de sublimar ou de fazer sinthoma, de singularizar-se, de canalizar as energias para realizar, ainda que parcialmente, o seu desejo de saber e de ser. E isso significa também in-screver-se (lt.: in scribere), ao se ex-screver (lt.: ex scribere), na medida em que muito de subjetivo percorre o caminho árduo, mas prazeroso da aprendizagem de uma língua que, como já dissemos, é muito mais do que conhecer a gramática, a cultura, como modo de viver, hábitos, costumes, é abrirse para o outro, deixando-se modificar, sem pretender ser o outro.

\section{Alguns Alinhavos...}

Como, então, proceder para enlaçar o aluno na rede do saber e não apenas do conhecimento? Criando - a escola e o professor - estratégias para enlaçar o aluno na rede do saber e não apenas na do conhecer (CORACINI, 2014), rede que é preciso tecer na tessitura da subjetividade, do corpo singular de cada um. Trabalhar com computador, iPad, imagens, internet pode ser uma forma de atrair a atenção do jovem, mas não é suficiente nem o mais importante, porque não passa de um meio, como o vídeo e os filmes fixos do passado recente. Adotar uma metodologia inovadora, que, diga-se de passagem, nunca é inteiramente nova, também não basta. É preciso, repetimos, enganchar o desejo do aluno ou fazê-lo vir à baila, se estiver adormecido pelo consumo exacerbado ou pelo vazio de uma vida feita de aparências, barulho e movimento. E enganchar o desejo do aluno no desejo do professor não significa levá-lo a realizar o que o professor, o pai ou a mãe querem, mas, ao contrário, a buscar a realização de seu próprio desejo, ainda que parcial, já que pouco se sabe dele, a não ser que só há desejo porque há falta, e há falta porque a linguagem é faltosa, é equívoco, é plural, e o sentido, disseminado (DERRIDA, 2001).

Apenas a posição subjetiva do professor, funcionando como sujeito suposto saber, professor engajado nos aspectos culturais e políticos do país, do estado, da cidade e da escola, seria capaz de dar espaço para que o aluno não limite o seu saber ao saber do professor, mas possa saber mais, adquirir conhecimentos outros que não apenas aqueles que o professor acredita dominar (ser senhor, dominus), despertando, assim, no aluno o desejo de aprender e de, sabendo línguas - a "sua" e a do outro (chamada língua estrangeira) - adentrar no mundo da pluralidade, onde o heterogêneo, o diferente, o estranho possam ter vez.

Desse modo, seria possível pensar em cidadãos criativos e conscientes de sua importância no mundo, que se caracteriza, hoje, na pós-modernidade, pela pluralidade, pelas sociedades que buscam preservar sua identidade, sua diferença linguístico-cultural ameaçada pelo fenômeno da globalização. Mas, para isso, é preciso que seja capaz de (se) dizer, de lutar e de se posicionar no mundo, ainda que este lhe negue um lugar (no caso dos excluídos por seu baixo poder aquisitivo). E, como já dissemos, só o professor desejante é capaz de despertar o desejo no e do outro. E ser professor desejante não é saber tudo, não é ser bilíngue, no sentido de saber duas línguas com perfeição (o que é impossível, embora constitua o ideal para muitos), mas perseguir incessantemente o saber, sempre lacunar, sempre falho, jamais completo, sobretudo porque uma língua não se deixa apropriar, não é propriedade de ninguém, não se deixa dominar - ninguém 
é o dominus, o seu senhor. Qualquer língua - primeira, segunda ou terceira - é de cada um e não é de ninguém (DERRIDA, 1996).

O professor desejante é aquele que gosta do que faz e o faz da melhor maneira possível com responsabilidade e amor. É aquele que hospeda em si o outro, aluno, com as suas diferenças e semelhanças. E sabemos que a acolhida do outro, a hospitalidade, que, em sala de aula, pode acontecer pela escrita de $\mathrm{si}^{6}{ }^{6}$ é prioritária para todos, mas, principalmente, para os jovens, num mundo em que a subjetividade de cada um está marcada pela indiferença do outro, pela autoanulação, pela depressão.

Finalmente, não podemos esquecer que vivemos, hoje mais do que nunca, divididos ou no entremeio confuso do sujeito do desejo e do sujeito do gozo, que não sabe a que veio, a não ser que deve consumir, consumir-se e, assim, sumir, levando sua singularidade, seu poder de transformar-se e de transformar o seu mundo e o mundo de seus semelhantes, ao desaparecimento, em prol do dinheiro, significante mestre na sociedade de consumo. ${ }^{7}$ E é, nessa sociedade, marcada pela instabilidade política, social e individual de um capitalismo desenfreado, ou, como querem alguns, avançado, mais do que nunca, que nós, professores, vivenciamos na pele, portanto, no corpo, a "(im)possibilidade de ensinar" e, ao mesmo tempo, a necessidade de fazê-lo, paradoxo que é preciso assumir e modificar, para que se atrofie o paradigma da verdade única, da racionalidade que, ainda hoje, domina certas ciências e, portanto, o modo de transmissão do conhecimento, para dar lugar ao saber múltiplo, heterogêneo, parcial, atrelado ao momento histórico-social e à cultura de um povo, de um grupo social, ao professor dedicado, que abdica de sua autoridade ímpar e intransmissível, da verdade única e irreversível, baseada na homogeneidade e na sequência espaço-temporal. Esse professor assume outra posição, mais adequada à pós-modernidade, na qual é preciso criatividade para enlaçar o aluno e ajudá-lo a buscar o seu desejo, a fazer algo de útil e produtivo com o seu sintoma, como afirma Lacan (2007). E terminamos com uma citação de Birman (2001, p. 27):

Este é o maior desafio hoje, certamente. Devemos reconstruir o sentido do que é educar, psicanalisar e governar num mundo que não se sabe mais o que é isso e que não se sabe responder para quê isso ainda nos serve. É diante desse desafio que devemos começar [ou, acrescentaríamos nós, continuar] já a fazer as nossas apostas no futuro.

\section{REFERÊNCIAS}

ANDRÉ, Serge. Le transfert de Lacan. Bruxelles: Le Bord de l'Eau, 2014.
BAUMAN, Zigmunt [1998]. Globalização: as consequências humanas. Trad. de Marcus Penchel. Rio de Janeiro: Jorge Zahar, 1999.

BAUMAN, Zigmunt. Modernidade líquida. Trad. de Plínio Detzien. Rio de Janeiro: Jorge Zahar, 2001.

BAUMAN, Zigmunt [2004]. Identidade. Trad. de Carlos Alberto Medeiros. Rio de Janeiro: Jorge Zahar, 2005.

BIRMAN, Joel. Subjetividade, contemporaneidade e educação. In: CANDAU, Vera Maria (Org.). Cultura, linguagem e subjetividade no ensinar e aprender. 2. ed. Rio de Janeiro: DP\&A, 2001.

CHARLES, Sébastien O individualismo paradoxal: introdução ao pensamento de Gilles Lipovetsky. In: LIPOVETSKY, Gilles; CHARLES, Sébastien. Os tempos hipermodernos. Trad. de Mário Vilela. São Paulo: Barcarolla, 2004. p. 13-48.

CORACINI, Maria José. Um fazer persuasivo: o discurso subjetivo da ciência. Campinas: Pontes; São Paulo: EDUC, 1991.

CORACINI, Maria José. O discurso da linguística aplicada e a questão da identidade: entre a modernidade e a pós-modernidade. In: CORACINI, Maria José; BERTOLDO, Ernesto S. (Org.). O desejo da teoria e a contingência da prática: discursos sobre e na sala de aula. Campinas: Mercado de Letras, 2003. p. 87-115.

CORACINI, Maria José. A escrita de si na internet: histórias ao acaso e o acaso das histórias. In: SCHONS, Carme R.; RÖSING, Tânia M. K. (Org.). Questões de escrita. Passo Fundo: UPF Editora, 2005. p. 42-54.

CORACINI, Maria José. Entre adquirir e aprender uma língua: subjetividade e polifonia. Bakhtiniana - Revista de Estudos do Discurso, v. 9, n. 2. p. 4-24 (port.); p. 5-27 (Engl.), 2014.

DERRIDA, Jacques [1972]. A farmácia de Platão. Trad. de Rogério da Costa. São Paulo: Illuminuras, 1991.

DERRIDA, Jacques. Le monolinguisme de l'autre. Paris: Galillée, 1996.

DERRIDA, Jacques. [1972]. Posições. Belo Horizonte: Autêntica, 2001.

DERRIDA, Jacques. Papel-máquina. São Paulo: Estação Liberdade, 2003.

FOUCAULT, Michel. L'ordre du discours. Paris: Gallimard, 1971.

FOUCAULT, Michel. Surveiller et punir. Paris: Gallimard, 1975.

FOUCAULT, Michel. A escrita de si. In: FOUCAULT, Michel. O que é um autor? Lisboa: Passagens. 1992. p. 129-160.

FOUCAULT, Michel (Coord.). Eu, Pierre Rivière, que degolei minha mãe, minha irmã e meu irmão: um caso de parricídio do século XIX apresentado por Michel Foucault. Trad. de Denize Lezau de Almeida. Rio de Janeiro: Graal, 1997.

FREUD, Sigmund [1920]. Além do princípio do prazer. In: Edição standard brasileira das obras psicológicas completas de Sigmund Freud. 2. ed. Rio de Janeiro: Imago, 1987.

FREUD, Sigmund. [1930] O mal-estar na civilização. Edição standard brasileira das obras psicológicas completas de Sigmund Freud. Rio de Janeiro: Imago, 1987. v. 18.

HUTCHBY, Ian. Conversation and technology: from telephone to the internet. Cambridge: Polity Press, 2001. 
KUPFER, Maria Cristina Machado. Freud e a educação: o mestre do impossível. 2. ed. São Paulo: Scipione, 1992. (Coleção: Mestres da Educação).

LACAN, Jacques [1966]. O estádio do espelho como formador da função do eu. In: LACAN, Jacques. Escritos. Trad. de Vera Ribeiro. Rio de Janeiro: Jorge Zahar, 1998a.

LACAN, Jacques. [1966]. A instância da letra no inconsciente ou a razão desde Freud. In: LACAN, Jacques. Escritos. Tradução de Vera Ribeiro. Rio de Janeiro: Jorge Zahar, 1998b. p. 496-533.

LACAN, Jacques. [1969-1970]. Seminário 17: o avesso da psicanálise. Rio de Janeiro: Jorge Zahar, 1992.

LACAN, Jacques. [1971]. Seminário 18: de um discurso que não fosse semblante. Rio de Janeiro: Zahar, 2009.

LACAN, Jacques. [1975-1976]. Seminário 23: o sinthoma. Trad. de Sérgio Laia. Rio de Janeiro: Jorge Zahar, 2007.

LEVENTHAL, Robert S. Jean François Lyotard, the differend: phrases in dispute. Minneapolis: University of Minnesota Press, 1991. Disponível em: <http://www2.iath. virginia.edu/holocaust/lyotarddiff.html>. Acesso em: 17 nov. 2014

LIPOVETSKY, Gilles. Metamorfoses da cultura liberal. Trad. de Juremir Machado da Silva. Porto Alegre: Sulina, 2004.

LIPOVETSKY, Gilles; SÉBASTIEN, Charles. Os tempos hipermodernos. Trad. de Mário Vilela. São Paulo: Barcarolla, 2004.

LYOTARD, Jean-François. La condition postmoderne: rapport sur le savoir. Paris: Minuit, 1979.

MASCIA, Márcia A. Amador. Investigações discursivas na pós-modernidade: uma análise das relações de poder-saber do discurso político educacional de língua estrangeira. São Paulo: Fapesp; Campinas: Mercado de Letras, 2003.
MELMAN, Charles. L'homme sans gravité. Paris: Denoël, 2002.

O ESTADO DE SÃO PAULO, 10 out. 2005.

RANCIÈRE, Jacques. O mestre ignorante. 3. ed. Trad. de Lílian do Valle. Belo Horizonte: Autêntica, 2010.

USHER, Rubin; EDWARDS, Richard. Postmodernism and education. London; New York: Routledge, 1994.

\section{Notas}

1 Tradução da autora. Em inglês: "In the Postmodern Condition, there is not one form of discourse that stands above all others; there is not one form of knowledge that is privileged and serves as the ground for all others. Rather, there is simply a multiplicity of various language games, a term which Lyotard borrows from the later Wittgenstein. The basic idea that Lyotard borrows from Wittgenstein is: of you want to know the meaning of a term, a phrase or a sentence, look at how it is utilized, how it functions in human interaction".

2 A primeira data, entre colchetes, refere-se à edição original; a segunda, ao texto traduzido utilizado. Note-se que as duas datas serão referidas apenas na primeira vez; nas demais, figurará apenas a data da obra efetivamente utilizada.

3 As aspas colocadas nas palavras "avanço" e "progresso" pretendem incutir no leitor certa dúvida quanto ao aspecto positivo que parece constituir sua semântica. Para o questionamento da noção de progresso, ler Coracini (1991) e Mascia (2003).

4 Esse filme pode ser encontrado no seguinte link: <http://www.youtube. $\mathrm{com} /$ watch? $\mathrm{v}=\mathrm{g} 5 \mathrm{~W} 7 \mathrm{mfOvqmU}>$.

5 O filme citado pode ser encontrado no seguinte link: $<$ http://www. filmesonlinegratis.net/escritores-da-liberdade-dublado.html $>$.

6 A escrita de si difere muito da escrita escolar, predeterminada pelo livro didático ou pelo(a) professor(a). Ler Coracini (2005).

7 Ver Birman (2001) a respeito.

Artigo recebido em julho 2014

Aprovado em novembro 2014. 